\title{
FOUR
}

\section{THE TECHNOLOGY OF PALEOLITHIC CLOTHES}

$\mathrm{T}^{\mathrm{s}}$ he invention of simple clothing was not a single event. During the course of hominin evolution, our ancestors would have adopted simple clothes many times whenever they found themselves exposed to cold as the climate changed during the Pleistocene. With simple clothes they could survive in cool environments up to a certain point, and they could often manage without clothes in summer or drop clothes completely when the climate warmed up again. However, they could only remain permanently in colder environments if they had complex clothes and, once equipped with complex clothing, they could stay in those places for as long as they wished. And then, at some stage, clothes became fashionable.

We can trace this process in the archaeological record by seeing how the early development of clothing was related to climate change. We can also see how the need for clothes became uncoupled from climate after complex clothing came into existence. To do this, we need to realize that although clothing is largely invisible in prehistory, it has left some visible traces. These traces are mainly technological: the tools that were used to manufacture clothes. $^{\text {I }}$

\section{SCRAPERS AND SIMPLE CLOTHES}

To make clothes from animal skins, the basic tools needed are scrapers. A skin can be separated from a carcass with various implements, but cleaning the 
table 6. Archaeological evidence for Paleolithic clothes

Sources of archaeological evidence for Paleolithic clothes.

\begin{tabular}{ll}
\hline \hline Technologies & $\begin{array}{l}\text { Scraping, cutting, and piercing implements } \\
\text { (e.g., scrapers, blade-based tools, awls, and needles) }\end{array}$ \\
Raw materials & $\begin{array}{l}\text { Faunal / plant exploitation (e.g., faunal targeting) } \\
\text { Animal body part distributions (suggesting skin removal) }\end{array}$ \\
Known physiological limits to human cold tolerance \\
Knferred presence & $\begin{array}{l}\text { Reconstructed thermal conditions / minimal clothing levels } \\
\text { Cold adaptations (e.g., Neanderthal body shape) } \\
\text { Anatomical }\end{array}$ \\
& Other (e.g., toe morphology - use of shoes) \\
\hline
\end{tabular}

inside surface is best done with proper scraping tools. Natural shells were used by hunter-gatherers where available, and people in coastal areas often used marine shells as hide-scrapers. But the most common scraper tools found by archaeologists were made from stones. The more clothes were worn, the more worthwhile it was for people to invest in making these scraper tools.

For simple clothing, scrapers were usually the only specific type of tool utilized. As we shall discover in the next chapter, there is plenty of archaeological evidence for scrapers in the Pleistocene. Indeed, one of the major technological trends before the last ice age was the advent and spread of Paleolithic industries based on scrapers. These scraper toolkits are good evidence for the invention and use of simple clothing. In a moment we shall look at how the distribution of these industries coincided with the changing climates - based on the physical need for simple clothes.

\section{COMPLEX CLOTHING TECHNOLOGIES}

To make complex clothing, scrapers were still needed, but some extra tools were also useful because people needed to do two extra things with the skins. First, the skins had to be cut into certain shapes, such as rectangles and triangles. Second, the cut pieces had to be joined together. These two activities precision-cutting and hole-piercing - are the two extra steps required to make fitted garments, such as shirts with sleeves and trousers with separate legs. Using Paleolithic technology, the hides could still be cut with stone scrapers, but it was best to have tools with a long sharp edge. Stone tools with long sharp edges look different to scrapers; we call them blades.

\section{Blade Tools}

Toolkits with blades can be a sign of complex clothing, and these blade industries became more common as humans were exposed to colder climates. The distribution of blade toolkits in relation to changing climates represents good 


\section{Simple clothing}

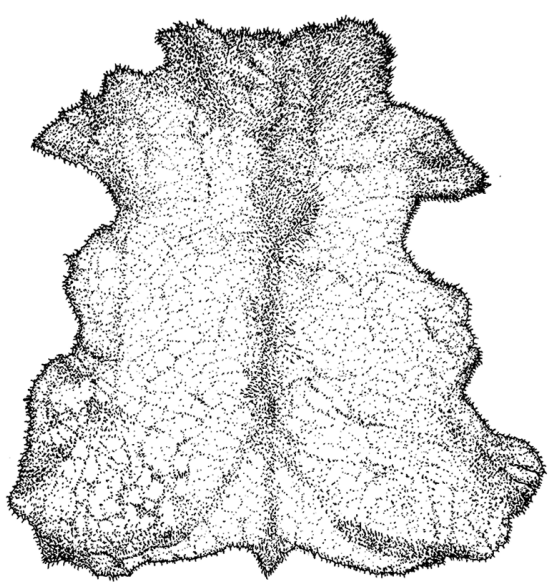

animal skin / fur

\section{Complex clothing}

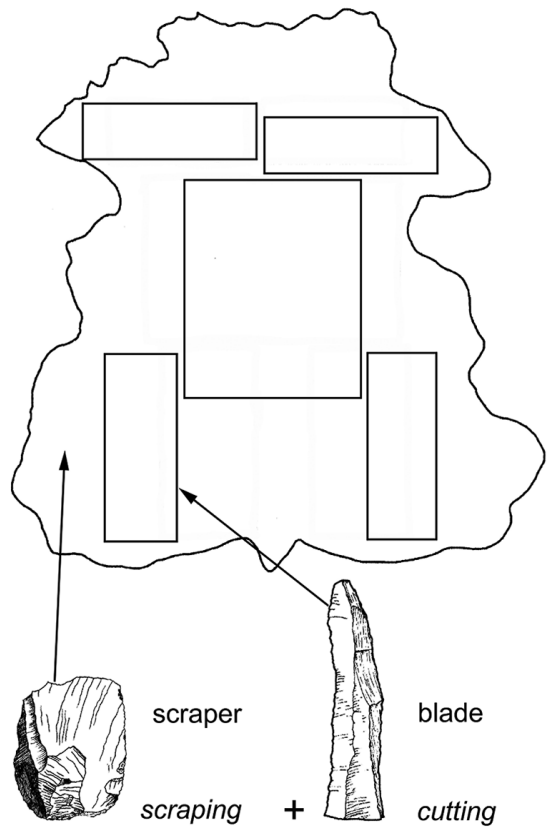

draped, single layer

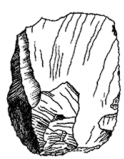

scraping tools

stone hide scraper

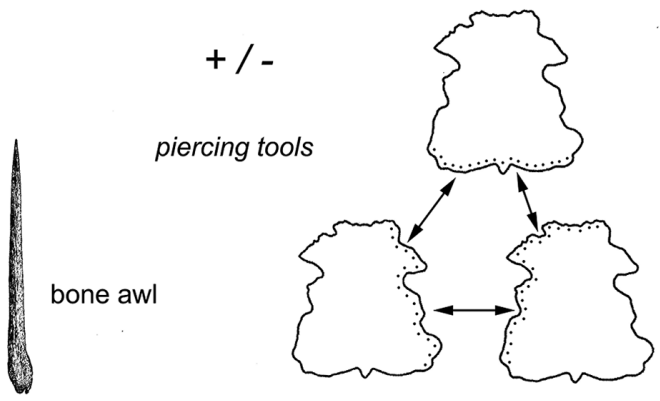

- for sewing small hides into larger cloaks fitted $+/$ - multiple layers

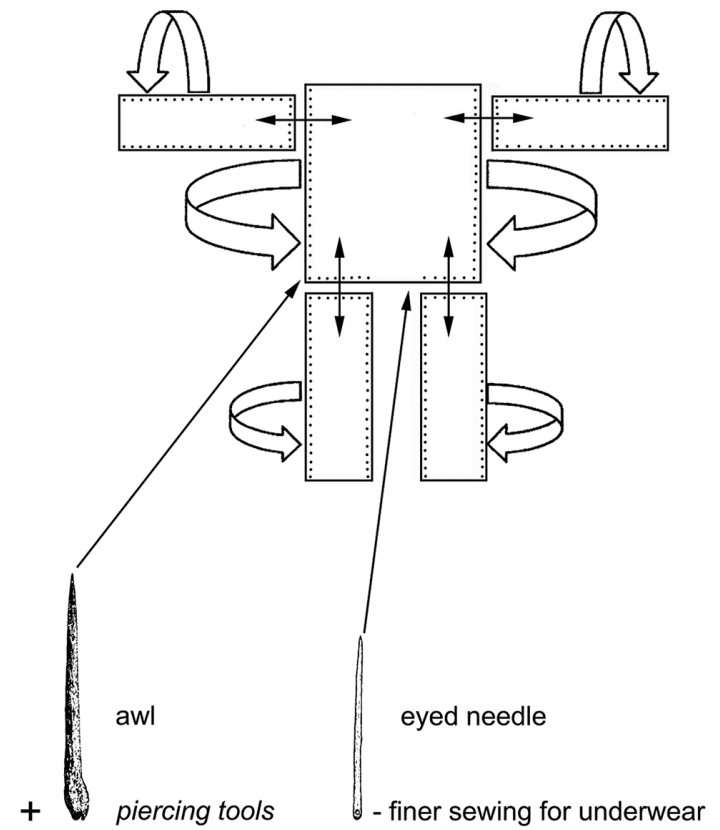

30. Paleolithic technology of simple and complex clothing

Technological aspects of simple and complex clothing in the Paleolithic. With simple clothes, the main technology is a scraper tool, with the addition of a piercing tool if multiple skins are sewn together to make a cloak. Complex clothes require scraper tools and, in addition, cutting implements (such as blades) and piercing implements (awls and needles). Eyed needles are particularly useful for making multilayered garment assemblages, facilitating the finer sewing required to make undergarments. 
evidence for the thermal invention of complex clothing, and it shows how complex clothing enabled humans to spread into the coldest environments.

\section{Piercing Tools}

The second type of tool needed for complex clothing is a piercing tool, so that the hide segments can be sewn together. Scraper tools can sometimes be used for this purpose as well, if they have a pointed corner, but more typical are pointed hide-piercing tools called awls. Awls were often made from long animal bones that could be shaved and shaped into awls more easily than stones. Finer bone awls are called needles, and those with holes drilled at one end are the classic eyed needles. With the archaeology, one indication that clothing played a role in promoting these technological innovations is that both of these technologies (blades and awls) came together in the coldest environments of the last ice age.

\section{FUNCTIONAL DIFFERENCES BETWEEN SCRAPERS AND BLADES}

Archaeologists traditionally define different kinds of tools mainly on the basis of their shape (and to a lesser degree, on the different techniques that were used in their manufacture). We are naturally inclined to assume that these different shapes correspond to different functions. For instance, a hammer has a different shape to a screwdriver, and these tools have different functions. One of the basic differences in Paleolithic tools is the difference between scrapers and blades. We assume a functional difference: scrapers were used for scraping and blades for cutting. In relation to Paleolithic clothing, we can make a simplistic distinction between scrapers and blades: scrapers were used to scrape hides and blades to cut hides. This corresponds to the difference between simple and complex clothing: simple clothing requires only scrapers whereas complex clothing benefits from having blades as well as scrapers.

\section{Tool Shape and Function}

Things are a little more complicated in the real world. The relationship between shape and function is far from clear-cut: scrapers can be used for cutting and blades for scraping. We are probably all guilty of blurring this boundary too: we might sometimes use a screwdriver as a hammer (but come to think of it, some of us are not very good with a hammer either). Blades can be defined primarily on the basis of shape: a blade is more than twice as long as it is wide, for instance. This corresponds loosely with function, but only loosely. By virtue of its shape, a blade maximizes the length of the cutting edge. In fact some archaeologists explain the advent of blades in terms of 
efficiency: a blade maximizes the amount of cutting edge extracted from a piece of stone - it is a more efficient use of the stone. This is true, of course, but the need for efficiency still relates to the desire to produce a cutting edge. In general, microscopic use-wear studies of Paleolithic tools confirm that the functional distinction between scrapers and blades is really rather loose. However, if we accept that tool shape is only loosely indicative of function, the overall distinction actually holds up fairly well. ${ }^{2}$

\section{Multipurpose Tools}

There are more complications though, as usual. In real life most tools would have been used for more than one purpose. And in terms of the origin, the first reason to invent a particular kind of tool - if we can put it that simplistically may not be the main reason why it was used later. Indeed its main functions may have varied over time and in different places. Neither can we assume that the final form of a tool - the one found by archaeologists when they excavate a site - necessarily reflects the original intention of its maker. The tool may have been reworked into different shapes during the course of its useful life, and it may have been reworked at different times by different people. The final product - be it a classical scraper or a blade, for instance - might in fact have undergone a number of transformations in shape and been used at different times for different purposes. Even assuming that a particular tool's final shape reflects its maker's original intention, the actual shape may be rather ambiguous. A stone point, for instance, might also function as a scraper if it has a more triangular shape - and it may in reality have served both as a hide-scraper and a hide-piercer. In terms of shape, it may be difficult - and misguided - to make a distinction between a point and a scraper. So to talk about scrapers and blades in a simplistic fashion as single-function tools based on their shape is rather fallacious, and it is certainly open to criticism - a criticism that is quite valid, technically. ${ }^{3}$

\section{Manufacturing Techniques}

An alternative approach with Paleolithic tools is not to classify them on the basis of their final shape but on the techniques used in their manufacture. This is a specialized area of research, but as an example, we can consider one of the main techniques used by Neanderthals in the manufacturing of their stone tools. The technique is called Levallois - and it was used also by Homo sapiens in some places. The Levallois technique involves first preparing the stone core by striking off flakes around its edges, then striking a blow across the core to extract a tool that has preformed sharp edges. The end result is a tool that is especially useful for scraping, with a maximum length of sharp scraping edge. 


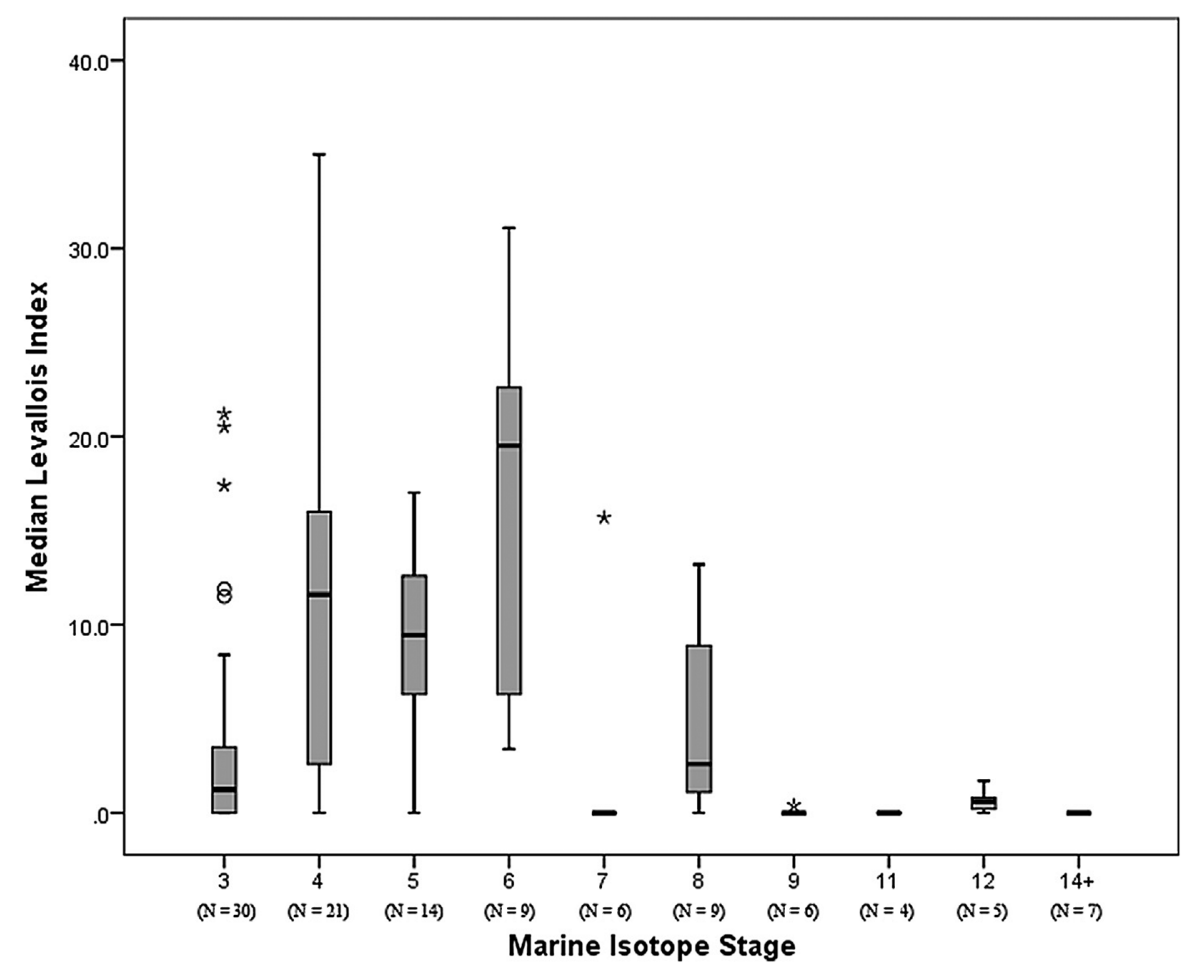

3 I. Levallois tool-making technique and glacial episodes

Levallois Index by Marine Isotope Stage (MIS). Lower and upper edges of boxes represent the 25th and 75 th percentiles; the bold horizontal lines inside the boxes indicate the statistical median; asterisks indicate outliers; and circles indicate extreme cases. Note the climate pattern: higher Levallois Index in the even-numbered MIS stages, corresponding to colder (glacial) episodes.

Source: Redrawn from Monnier and Missal, 2014:73. (C) Elsevier. Reproduced under license.

The classic scraper tools used by Neanderthals were generally made in this manner, and it represents a more sophisticated technology than its predecessors. Later, we shall look at the climate trends in stone tools during the Pleistocene, but it is worthwhile mentioning here the research into how the Levallois technology varied in relation to the cold episodes. As shown in the graph, the Levallois technique - as a stone-knapping method that maximizes the useful scraping edge - fluctuates in concert with climate, reaching peaks during the glacial phases. ${ }^{4}$

\section{Many Materials}

Another complication with Paleolithic tools relates to the kinds of materials that the tools were used on. Use-wear studies show that most of the tools, blades and scrapers, were used not just to work on animal hides but on other materials as well. Butchering meat and woodworking were common functions 
in many cases, and often the same tool can show traces of being used on more than one kind of material. And it is not always easy to distinguish the functions or the materials; traces of hide-working, for instance, are notoriously hard to detect on older tools. Given the diversity in function and the loose connections with tool shape, some archaeologists argue that the differences in tool shape should not be used to infer functional differences. Nevertheless, functional diversity notwithstanding, there is good evidence from use-wear studies to support an overall distinction between scrapers and blades in relation to the manufacture of clothing.

\section{SCRAPERS, BLADES, AND CLIMATE CHANGE}

Support for this functional difference between scrapers and blades comes from use-wear studies at a European ice age site near the village of Pavlov, in the Czech Republic (latitude $50^{\circ} \mathrm{N}$ ). The site was occupied by Homo sapiens between 29,000 and 23,000 years ago, leading into the LGM. Archaeologists looked at the use-wear patterns on scraper and blade tools and they found that hide-working was the most common function for both scrapers and blades no real surprise there. But when they looked more closely at the traces on the working edges, they discovered a striking difference between scrapers and blades.

With scrapers, the traces on the edges of the tools were produced by a transverse motion on the hides - meaning that the scrapers were used with a sideways scraping motion. With the blade tools, they found the opposite pattern: the blades had a longitudinal wear pattern. That is, the working edges of the blades showed a lengthwise wear pattern - the blades had clearly been used for cutting rather than scraping the hides. So at this site in the last ice age where both scrapers and blades were used on animal hides, there was a difference in tool function: scrapers were indeed used to scrape animal hides whereas the blades were used to cut the hides. ${ }^{5}$

Another place where we see these trends is at Qesem Cave in Israel $\left(32^{\circ} \mathrm{N}\right)$, which has some of the earliest scraper and blade industries in the world. Humans first occupied this cave during the very warm MISII interglacial around 400,000 years ago. The scraper industry begins toward the end of MIS I I and spans the MIS Io glacial, from around 370,000 to 330,000 years ago. The blade industry spans the following MIS8 glacial, from 300,000 to 240,000 years ago. So at this one remarkable site where early scraper and blade industries are found, the scrapers precede the blades, and both of these tool innovations correspond closely to climate change - namely, cold episodes. ${ }^{6}$

Use-wear analysis of the Qesem Cave tools also revealed the same functional difference between the scrapers and blades seen at Pavlov: the scrapers were used mainly for scraping and the blades for cutting. ${ }^{7}$ 

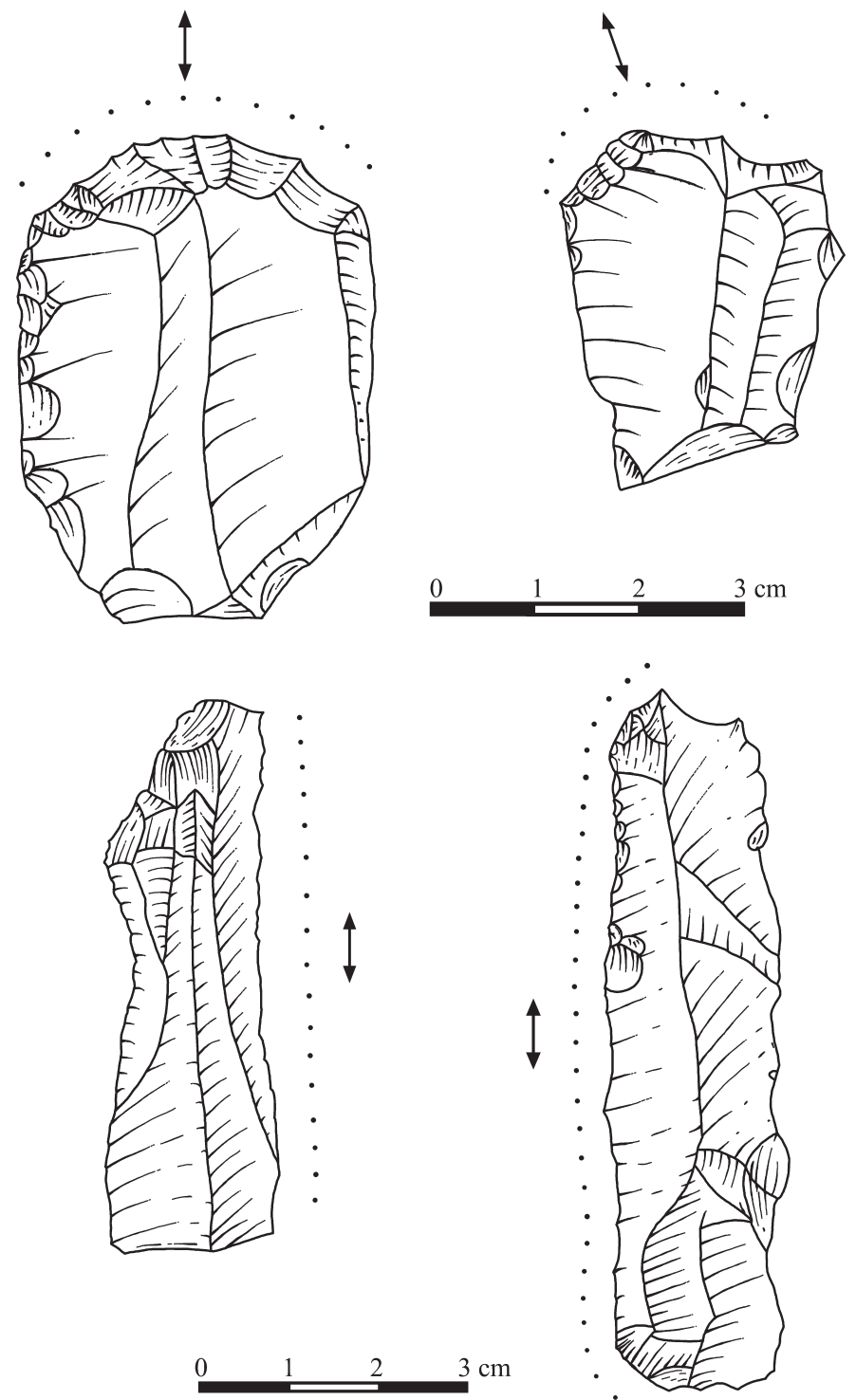

32. Different use-wear patterns on scrapers and blades

Scrapers and blade tools can have differing functions in the manufacture of clothing. Use-wear findings from the Pavlov I site in the Czech Republic, dated between 28,000 and 25,000 years ago, indicate that the scrapers (top) were used with a transverse (scraping) motion on animal hides whereas blades (bottom) were used with a longitudinal (cutting) motion.

Source: Šajnerová-Dušková, 2007:35, 36. Reproduced by permission of Archaeopress, and courtesy of Andrea Dušková and Jiří Svoboda.

\section{THE TECHNOLOGICAL VISIBILITY OF PREHISTORIC CLOTHES}

These Paleolithic technologies allow us to see the invisible clothing that was made by hominins in the Pleistocene. And insofar as they may serve as proxies for clothing, the tools allow us to test the proposition that clothing was developed as a 
means of keeping warm. We can see how simple clothing first came into existence (and sometimes went away) and how it was developed into complex clothing when environmental conditions got more challenging. And we can discern both aspects of complex clothing - the fitting of garments and the extra layers. Multiple layers demanded more careful cutting and sewing, especially for the underwear, which led to the invention of the eyed needle.

\section{Awls in Australia}

Australia illustrates some of the issues nicely. Its temperate climate meant that complex clothing was never developed, so we do not find classic blade industriesand nor do we find eyed needles - during the Pleistocene. However, in cooler areas of the continent simple clothing was required at times - more so as the LGM approached. And as we shall see later, scraper industries were developed in the most southerly region - Tasmania - during the LGM. The other technology that

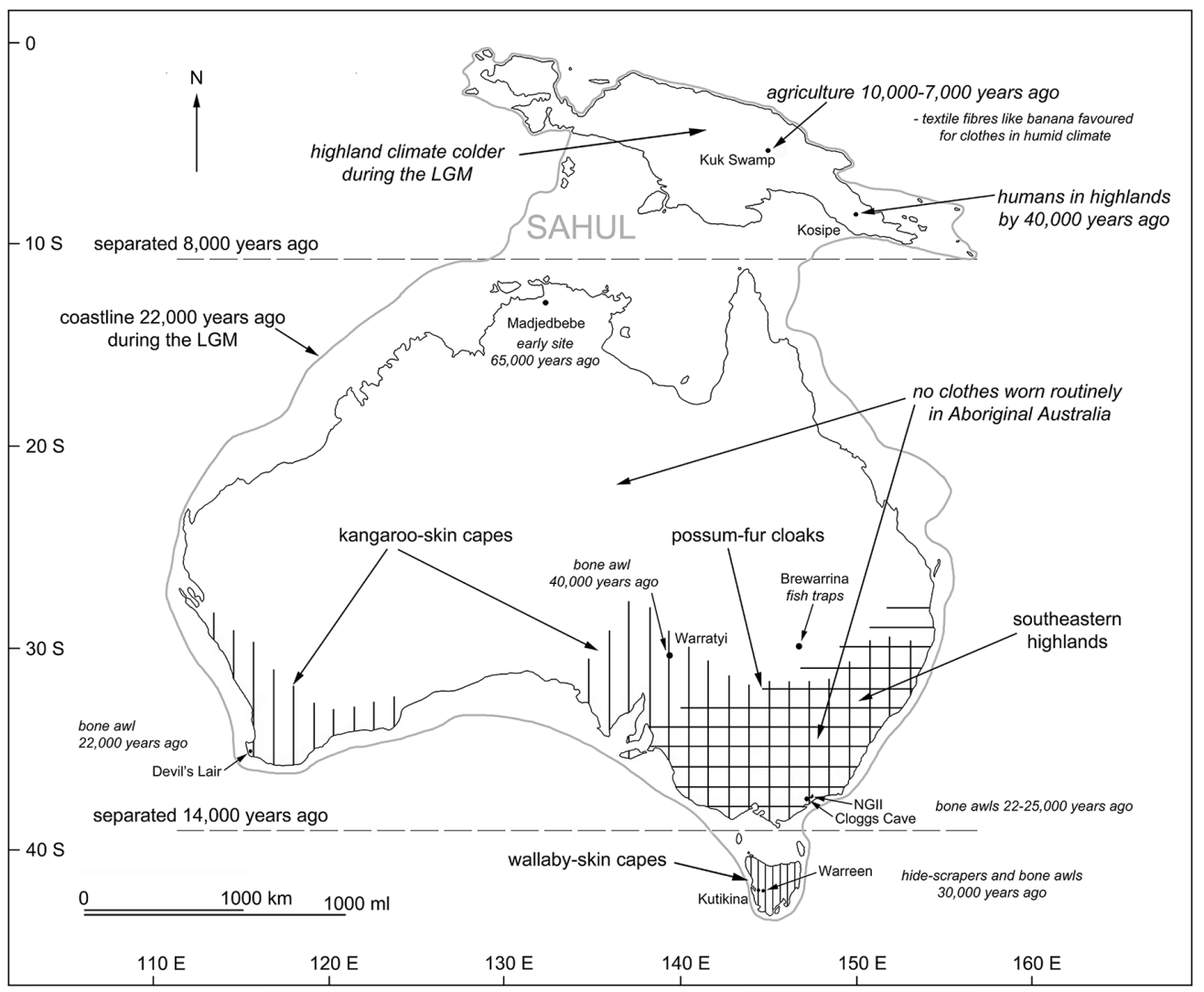

33. Map of Australian region

Australia, Tasmania, and New Guinea were joined together as one continent - called Sahul during the last ice age, due to lowered sea levels. Shown here are key archaeological sites relevant to the early development of clothing technologies, and the ethnographic distribution of the major forms of clothing used in Aboriginal Australia: kangaroo-skin cloaks, possum-fur cloaks, and in Tasmania, wallaby-skin capes. 
appears in Australia is the bone awl, which was used by people to sew smaller animal skins into larger cloaks - like possum-fur cloaks.

One of the earliest bone awls was found at Cloggs Cave in the southeast, dated to 22,000 years - the time of the LGM. Cloggs Cave has scrapers too, and the nearby site of NGII has a number of bone points, dated to around 25,000 years ago; use-wear patterns on the points are consistent with their function as awls for piercing animal skins. Across the continent in the southwest, a bone point was found in a level dated to the LGM (22,000 years ago) at the Devil's Lair cave site. Although no use-wear analysis was done on this artifact, it is very similar to bone points used by Aborigines in recent times to pierce holes in animal skins. Another bone artifact at Devil's Lair is a small triangular bone point that may have functioned as an awl, dated to between 32,000 and 25,000 years ago. The earliest bone point found in Australia - said
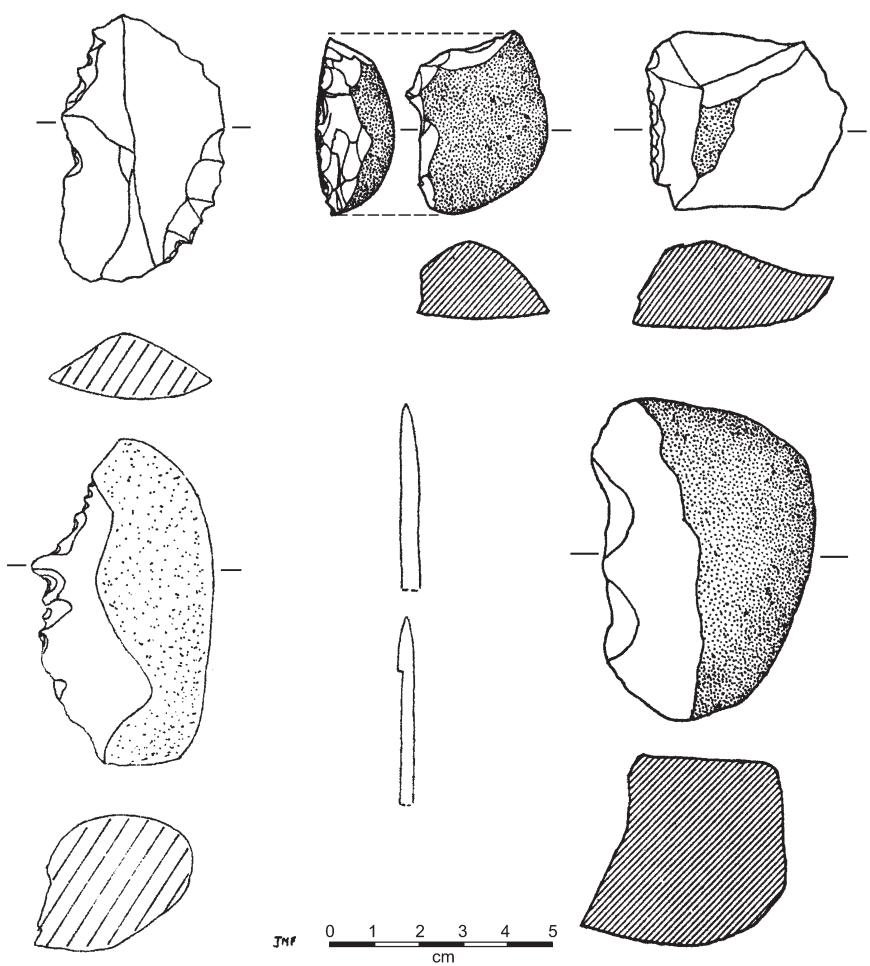

JN

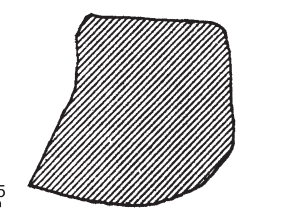

34. 22,000-year-old scrapers and bone awl at Cloggs Cave, Australia

Stone tools and a bone point (lower center) from Cloggs Cave, southeastern Australia, dated to around 22,000 years ago - the time of the LGM. The site was excavated in the early I970s by archaeologist Josephine Flood, who thinks these tools were used mainly for skin-working and that the bone point functioned as an awl for sewing animal skins together to make cloaks.

Source: Illustration by Josephine Flood (Flood, I974:183). Reproduced by permission of John Wiley and Sons, and courtesy of Josephine Flood. 

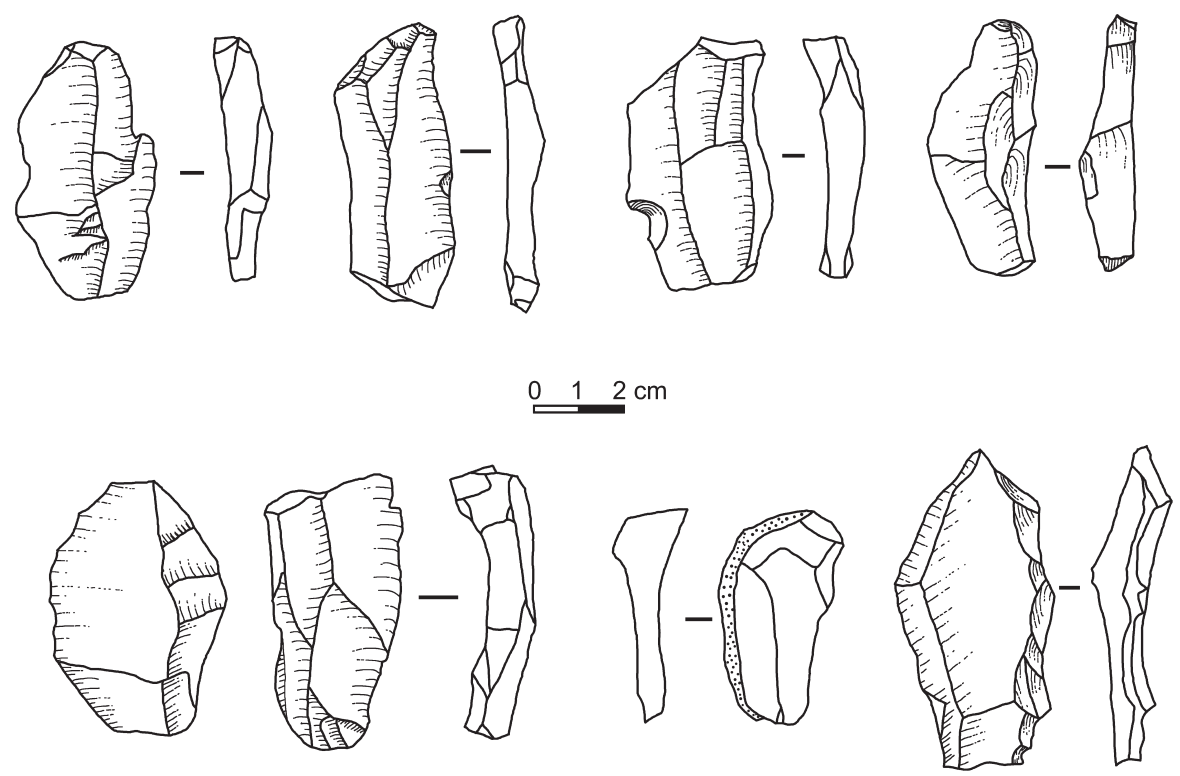

35. 40,000-year-old blades in northern China

Blade tools appeared in China around 40,000 years ago at the Shuidonggou (SDGI) site in northern China.

Source: Peng, Wang, and Gao, 20I4:I6. (C) Elsevier. Reproduced by permission of Elsevier.

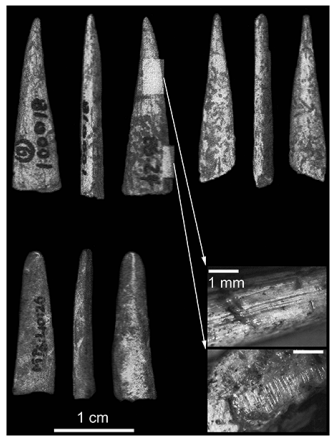

36. 35,000-year-old bone awls in China

35,ooo-year-old bone awls found at Ma'anshan Cave, Guizhou Province, in central eastern China. Microscopic study shows evidence of polishing near the tips of the awls and scraping, as shown here (lower right), consistent with repeated grinding to maintain their sharpness for piercing animal skins.

Source: Zhang et al., 2016:63, (C) Elsevier. Reproduced under license, Elsevier. to look like an awl - was recovered from the Warratyi rockshelter in the southern interior, dated to between 40,000 and 38,000 years ago. ${ }^{8}$

Blades, Awls, and Needles in China

China also illustrates some of the main points about the archaeology of Paleolithic clothing and how the technologies were related to climate. We find the earliest blade industries in China around 40,000 years ago, at the site of Shuidonggou (SDGI, $38^{\circ} \mathrm{N}$ ) in northwest China. This was a fairly cold period and, in all likelihood, the first Homo sapiens to reach northern China had complex clothes. We then find the earliest bone tools in China around 35,000 years ago at the site of Ma'anshan Cave (latitude $28^{\circ} \mathrm{N}$ ) in central eastern China. Use-wear study of these bone points has identified them as awls for piercing animal skins. Then, as conditions became colder toward the LGM, we find the first eyed needles in China. One eyed needle was found at Shuidonggou dated to around 30,000 years ago, and a number of finely-made eyed needles have been found at the Xiaogushan cave site $\left(40^{\circ} \mathrm{N}\right)$ dated to between 30,000 and 20,000 years ago; while at the 
site of Shizitan $\left(36^{\circ} \mathrm{N}\right)$ in Shanxi Province, an eyed needle is dated to 26,000 years ago. ${ }^{9}$

\section{EYED NEEDLES AND UNDERWEAR}

The classic tool for complex clothing is the eyed needle. As expected, these fragile implements first made their appearance during the coldest times. Among the very first to appear anywhere in the world are found at the Russian site of Kostenki is (latitude $5 \mathrm{I}^{\circ} \mathrm{N}$ ) around 35,000 years ago - although the ones found at Denisova Cave (also $5 \mathrm{I}^{\circ} \mathrm{N}$ ) in southern Siberia could be a little earlier. The world's oldest may be at Mezmaiskaya Cave $\left(44^{\circ} \mathrm{N}\right)$ in southern Russia, where a single eyed needle has been found in a layer dated to between 40,000 and 36,000 years ago. ${ }^{\text {IO }}$

Eyed needles made their appearance later in Western Europe, where the winter temperatures were milder, beginning from around 30,000 years ago. They became more common toward the LGM - especially in the Solutrean industry, which spans the LGM. The timing of the Solutrean around 2I, ooo years ago corresponds to the coldest point of the LGM, so one of its hallmarks - eyed needles - likely reflects a heightened need for complex clothes. Moreover, climate reconstructions point toward a pronounced drop in winter minimum temperatures in Western Europe at precisely that time. However, it must be emphasized that the delayed appearance of eyed needles around I0,000 years later than on the exposed plains further east - does not mean that humans were somehow managing to survive without fitted garments when they first entered Western Europe around 40,000 years ago. Making fitted, sewn clothing does not required eyed needles at all - it only requires pointed tools like awls. And bone awls are present from around 40,000 years ago, in the Aurignacian industry that accompanied the entry of Homo sapiens into Western Europe. ${ }^{\text {II }}$

Eyed needles are the signature tools of tailoring, but they may actually signify something more specific than complex clothes: eyed needles suggest a greater focus on intricate sewing. Finer handiwork would have been most in demand to make the inside garments of multilayered outfits, so the advent of eyed needles may indicate not just fitted garments but the need for people to wear more than one layer of fitted garments. In other words, rather than signifying tailoring, the first eyed needles may mark the invention of underwear.

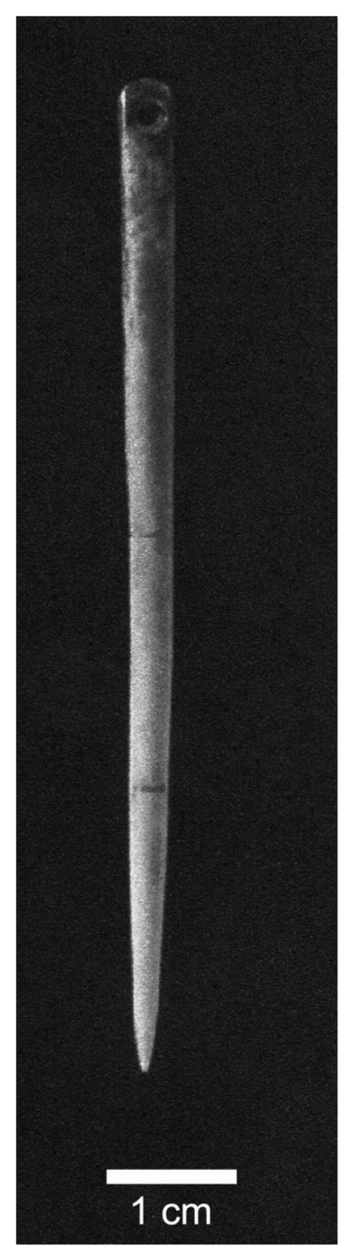

37. 30,000-year-old eyed needles in China Eyed needles are found in northern China during cold millennia leading into the LGM. One of the oldest eyed needles occurs at the Shizitan site, Shanxi Province (26,00o years ago), and another at the Xiaogushan cave site, which dates to between 30,000 and 20,000 years ago. Shown here is the eyed needle from Xiaogushan.

Source: Zhang et al., Journal of Human Evolution 59, 2010:5I7. (C) Elsevier. Reproduced by permission of Elsevier. 


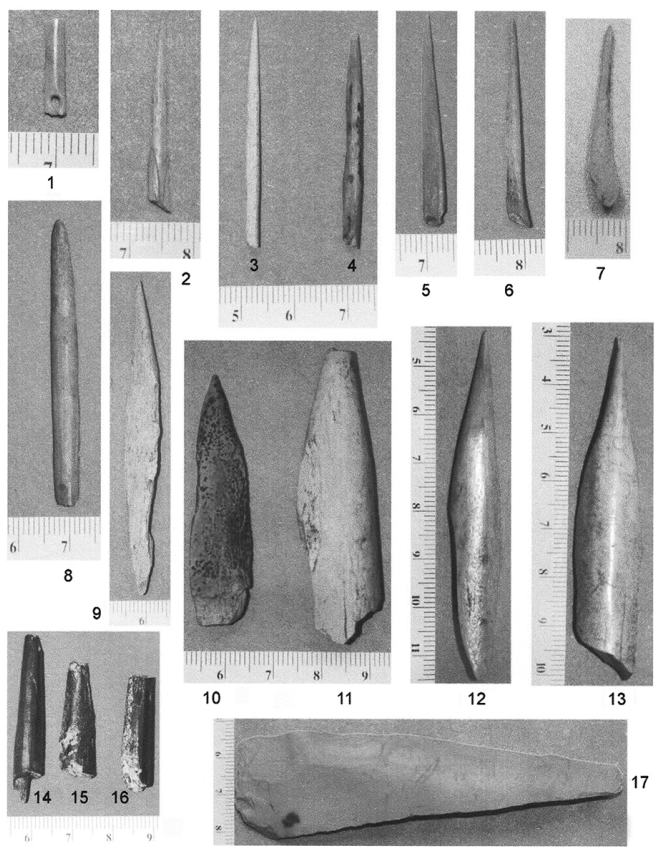

38. World's oldest eyed needle in Russia $\mathbf{4 0 , 0 0 0}$ years ago

The world's oldest eyed needle is between 40,000 and 36,000 years old, found at Mezmaiskaya Cave in southern Russia. The eyed needle fragment (numbered I here) is accompanied by other needles and bone awls in the cave in layers dated to between 40,000 and 28,000 years ago.

Source: Golovanova, Doronichev, and Cleghorn, Antiquity 84, 2010:308. Reproduced by permission of Cambridge University Press.
SKELETAL PARTS AND ANIMAL SKINS

Animal bones found at archaeological sites sometimes harbor another sign of Paleolithic clothing. Not only did people often target furry animal species - such as wallabies in ice age Tasmania - at some sites, archaeologists find that certain parts of the animal skeletons are not as common as they should be. The feet and tail bones, which are numerically common in the skeletons, are uncommon at the sites or completely missing. The likely reason is that people were not just butchering the carcasses for meat: they were carefully removing the skins from the animals. In removing the skins, they would often leave the tails and paws attached to the skins - to make them easier to carry, or to tie them around the body.

This pattern of separated skeletal elements is seen in colder parts of the world during the Pleistocene. For example, in Germany during the MIS, interglacial 300,000 years ago, hominins were hunting mainly horses. At the site of Schöningen, where lots of horse carcasses were butchered, hoof bones are much less common than expected, and tail bones are almost absent. The stone tools at Schöningen are mainly flakes, but some scrapers were also found. And use-wear traces on the scrapers show that the tools were used on hides as well as wood. Archaeologists also found deep cut marks on the horse leg bones, which could be due to skinning. The same kind of cut marks are seen also on many of the animal bones - including horses, sheep, hyenas, and felines - at one South African site dated to between 65,000 and 60,000 years ago (during the cold MIS4 glacial). At that time in southern Africa, we also find tool industries with blades and bone awls, as well as scrapers. Meanwhile in ice age Europe, the bones of wolves and arctic foxes at many Russian and Ukrainian sites show this same odd pattern of separated elements: skeletons lacking paws or, sometimes, paw bones found separately as complete paws. At Kostenki I, the partial skeletons of wolves and arctic foxes are found in Layer III, dated to between 38,000 and 34,000 years ago. Even 
cave lions were hunted for their pelts. At one cave in Spain, archaeologists found a collection of paw bones with the telltale cut marks showing how the pelt had been carefully removed from the carcass of the lion. And in Tasmania during the LGM when the Aborigines focused on hunting wallabies (and where we also find scrapers and bone awls), the wallaby skeletons likewise have a paucity of paw, foot, and tail bones, suggesting that people were carefully removing the skins. ${ }^{\text {I2 }}$ 